\title{
Momenter til et forsvar av tingene
}

BJøRNAR OLSEN

\begin{abstract}
Arkeologien er tingenes disiplin par excellence. Det var en gang da arkeologene elsket gjenstandene - noen vil kanskje til og med huske en viss besettelse. Men i takt med tingenes fallende intellektuelle kurs ble også arkeologenes kjærlighet satt på prøve. I denne artikkelen forsøker forfatteren å forklare hvorfor ting og materialitet fikk et så dårlig rykte i menneskevitenskapene - eller sagt på en annen måte: å forklare sviket mot tingene.
\end{abstract}

Jeg vil starte dette venneskriftet med en kort og høyst uautorisert biografisk skisse over mitt eget fags livslange forhold til tingene. Et forhold som nok utad har gitt inntrykk av trofasthet og harmoni - men hvor de innvidde kan berette om både gnisninger og til dels alvorlige sidesprang. Uansett, arkeologi som fag er nært knyttet til studiet av ting. Blant folk flest, og av de fleste andre disipliner, blir vi oppfattet som et gjenstandsfag. En gang for lenge siden delte vi skjebne med fag som etnologi, etnografi og antropologi, men med noe ulik kronologi, med ulik intensitet og med betydelige geografiske variasjoner, forlot de fleste av våre tidligere allierte tingenes verden og bega seg kulturene, de sosiale systemene og tankenes verdener i vold. Tingene, ble det sagt, ga begrenset adgang til det levde og tenkte, og de ble derfor skiftet ut til fordel for samtalen, den deltakende observasjon - eller, i den grad man ikke kunne konfrontere det tenkende og handlende mennesket direkte, med de skrevne kildene nedtegnet av andre bevisste mennesker.
Med tiden kom også mange arkeologer til å føle seg utilpass og forlegne med den ensomme rollen som tingenes forsvarere. Og gradvis merket man en endring i den arkeologiske retorikken: det var ikke tingene, men det sosiale og det menneskelige som var målet for vår virksomhet: The indian behind the artefact. Den forventete applausen uteble imidlertid og stadig flere grep til ordet for å advare mot tingenes umenneskelige utistrekkelighet. Noen tilfeldige eksempler: I 1951 fortalte Gutorm Gjessing - forhenværende merittert arkeolog som nylig hadde konvertert til etnografien - sine tidligere kolleger om hvor tilfeldig det arkeologiske materialet egentlig var og hvor lite egnet det var som kilde til sosial og kulturell forståelse. For, som han minnet om, "kulturen består overhodet ikke av gjenstander eller atferdsmønstre, men av det idéinnholdet som ligger bak de synlige manifestasjonene» (Gjessing 1951:220). Med samme utkikkspunkt kunne sosialantropologen Fredrik Barth ti år seinere angripe «gjenstandsforskerne» på følgende vis: «En har ofte følelsen av at kulturelle former, 
26 og til og med etterlatenskaper, behandles analytisk som om de var kulturelementer. Det skulle være klart.. at atferdsmønstre beskrevet som «skikker», eller gjenstander i et... museum, ikke er elementer av en kultur. Derimot er det fra slike vitnesbyrd at vi kan abstrahere en kultur - kulturen består av ideer" (1961:39)

Og på begynnelsen av 1970-tallet kunne nok en antropolog, denne gang Edmund Leach, fortelle oss at «in the last analysis, archaeology must be concerned with peoples rather than things» (Leach 1973:768). I hvert fall om man skulle ha noen forhåpninger om å samarbeide med antropologene. Og da positivismedebatten og den kritiske diskursen nådde oss (- som vanlig noe forsinket) ble vi nok en gang ydmyket og brakt i forlegenhet da det gikk opp for oss hva de kritiske filosofene hadde valgt som sine aller verste skjellsord: "tingliggjøring", "objektivisering". Det mest fornedrende et menneske, et individ, en sosial relasjon, kunne utsettes for. Tenk å bli gjort til en "ting” og ikke erkjent som aktør eller subjekt! Sett med den antropologiske og samfunnsteoretiske diskursens stadig økende klarsyn ble begrepet materiell kultur nærmest en selvmotsigelse. Og nylig kunne vi lese følgende melding i et av våre mest framstående arkeologiske tidskrift: "culture does not resides in material things, it resides in... meaningful human activity" (Handler 2003:354).

Men nå som subjektet har fått rådet grunnen så lenge er det kanskje på tide å rehabilitere tingen, bringe den tilbake fra sin forvisning i magasinenes mørke? Mottoet for en slik rehabilitering må være at kultur også er ting, at sosiale systemer og aktører også er materielle, og at kunnskap og ferdighet er noe mer enn bare ideer. Dette skriftet til Per-Uno er derfor ment som et innledende forsvar av det materielle (se Olsen 2003).

\section{FORPOSTFEKTING}

Mitt første forsvar er banalt, retorisk, men sant - og i hvert fall enestående effektivt i tilfelle du skulle gå deg fast i en diskusjon med en sosiolog, filosof eller antropolog. Tenk deg en situasjon, skal du da si, der vi plutselig fjernet all materiell kultur, og vi satt der fullstendig nakne med ideene og tankene våre rundt....? Ja, vi hadde vel ikke noe å sitte rundt, fordi bålet eller bordet jo er materielt. Egentlig spørs det om vi kunne sitte på noe, for marken og steinene også er materielle. Og strengt tatt er jo kroppene våre også det, så det ville vel bare være fornuften og tankene våre som svevde rundt i... ? Ja, hva skulle de sveve rundt i?

Men la oss være sjenerøse å la menneskene få ha kroppene sine, og jorda å sitte eller stå på, men at vi tok vekk alt det andre. Ville kulturen fortsatt være der, som ideer og tradisjoner? De sosiale institusjonene; handlinger og handlingsmønstre? Den kollektive hukommelse? Hva ville vi i eventuelt ha tapt, ha savnet? Teknologien og infrastrukturen? Selvsagt. Og sikkert også det symbolsk kommunikative, dvs. de semiotiske kvaliteter vi i dag som sosialt bevisste arkeologer, museologer, etnologer og antropologer tilskriver tingene.

Men ville dette være alt som gikk tapt, alt vi savnet - det teknisk-praktiske og det symbolskkommunikative? Eller er det noe mer, noe som inngår i skapningen av oss som mennesker og subjekter, og som vi kanskje ikke helt vet hva er, eller kan gi uttrykk for, før vi eventuelt har mistet det? Det vi kanskje kan kalle den materielle substans i vår tilværelse og eksistens.

På tross av at tingene og redskapsbruk ofte er brukt til å definere hva som gjør oss til mennesker, til å definere menneskelighet og følgelig hva som skiller oss fra våre nærstående slektninger i dyreriket, er tingene påfallende 
fraværende i samfunns- og kulturvitenskapelige analyser. Derfor fristes man til å samstemme i Michel Serres ytterst ironiske bemerkning om at "in the current state of affairs the socalled human or social sciences seem at best to apply only to animals" (Serres/Latour 1995:199-200). Foruten å være ment som et forsvar av tingene, skal jeg bruke dette venneskriftet til Per-Uno til å drøfte spørsmålet om hvorfor tingene (det materielle, teknologien) i så stor grad har blitt ekskludert fra den samfunnsvitenskapelige forskningen. Aller først, imidlertid, noen synspunkt på tingenes - og materialitetens - skjebne i nyere arkeologisk og antropologisk forskning.

\section{MistANKENS HERMENEUTIKERE}

Materiell kultur har hatt to grunnleggende identiteter i arkeologisk forskning: En knyttet opp mot dens funksjonelle praktiske betydning for menneskets reproduksjon; den andre knyttet opp mot dens rolle som tegn, metafor eller symbol. Denne dikotomien mellom tegn og teknologi, stil og funksjon, og debatten tilknyttet til den er velkjent og krever ingen repetisjon her (se Olsen 1997:176-188). Det er vel mer eller mindre kanonisert at tingene både kan ha en praktisk og en symbolsk kommunikativ funksjon. Men er denne dikotomien uttømmende for hva materiell kultur er? Har vi fyllestgjørende svart på spørsmålet når vi møysommelig har ledet ut tingens kommunikative og/eller teknologiske betydning? Eller gjenstår det fortsatt et fundamentalt spørsmål: om hvordan gjenstandene, tingene - allment, ontologisk betraktet - står til mennesket og det som i sin alminnelighet omtales som det kulturelle og det sosiale?

Dette spørsmålet har i forbausende liten grad blitt forsøkt besvart. Det begge de skisserte po- sisjonene har til felles er at materiell kultur, det materielle, ikke eller bare i liten grad inngår i målet for forskningen. Den er et middel til noe annet og mer, noe sosialt eller kulturelt som skulle befinne seg bortenfor tingene. En verden hinsides det materielle. Arkeologenes befatning med materiell kultur har derfor primært vært grunnet i epistemologiske eller metodologiske bekymringer: materialet sees på som en kilde som skal bringe fram noe viktigere og større enn seg selv: samfunn, kulturer, mentaliteter. Eventuelt økonomi, produksjon, miljø. Før vi kan spørre om hvorfor det er blitt slik, skal vi ta et lite sideblikk på hva som har skjedd i det siste årene hos noen av våre tidligere allierte.

For som de fleste har lagt merke til er vi ikke lenger alene på tingenes market. Fra midten av 1980-tallet av begynte materiell kultur på ny å interessere enkelte antropologer og forskere innenfor nye disiplinære konstruksjoner som «cultural studies», design studier, mediavitenskap, turist-studier, osv. Mye av dette faller under den paraplyen som på engelsk kalles «consumption studies» eller forbruksstudier (se Miller 1987, 1998a, 1998b, 2002; Dant 1999, Attfield 2000, Buchli 2002). I sin bok fra 1987, Material culture and mass consumption, begrunner Daniel Miller den nye interessen med at materiell kultur (i betydning av moderne materiell kultur) har unngått det akademiske blikket, og han sier det så sterkt at materiell kultur er det minst forståtte fenomen i vårt samfunn (Miller 1987:217). Han hevder at spesielt i det moderne samfunn, med dets tiltakende materialitet, skjer menneskenes sosiale skapning og kulturelle konstruksjon i minst like stor grad gjennom materiell kultur som gjennom språk.

Nyere antropologiske studier av moderne materiell kultur har i stor grad fokusert på hvordan mennesker gjennom sitt materielle forbruk 
28 og daglige omgang med ting konstruerer sosiale idealer og personlige og kollektive identiteter. Dette har ledet til et hav av studier av reklame, graffiti, kitsch, klær, kaffeservicer, tepper og hjemmeinnredning. Og i økende grad siden slutten av 1990-tallet, da fokuset mer og mer har blitt rettet mot shopping, vareflyt, begjæret for objekter, deres estetisering og medienes bilde av dem, heller enn hvordan ting brukes og blir levd med (Dant 1999:37, jfr. også Attfield 2000: 136 ff, Brown 2003:4, Glassie 1999:77-84).

Den svenske etnologen, Orvar Löfgren, har i en artikkel fra 1997 reist noen betimelige spørsmål ved de nye studiene av materiell kultur i antropologien og etnologien. Han påpeker hvordan de i stor grad er rettet mot det spesielle og det symbolske. Når du leser disse studiene av tenåringsvaner, hjemmeinnredning og shoppere, så får du følelsen av å befinne deg i en symbolsk jungel eller vandre gjennom en utstilling av meninger og beskjeder (Löfgren 1997). I denne fokuseringen på det symbolske er det dessuten en total dominans av det visuelle over de andre sansene. Syn blir nærmest det eneste medium vi erfarer verden gjennom, og vår relasjon til den materielle verden blir nærmest synonymt med det å betrakte, å se: som flanører, turister, tittere. Vi er ikke i verden, vi bare betrakter den (Welsch 1997). Dette har ifølge Löfgren overskygget vår egentlige væremåte i verden, selvsagt ser vi aldri bare. Hvordan kunne ellers en blind ta seg fram i verden, gå rundt i sitt hus, og eller føle livet meningsfylt? For Löfgren er det et paradoks at tilbakevendingen til studiet av ting i så liten grad betydde det materielles tilbakekomst (Löfgren 1997:102-103). Samtidig som mer og mer av våre liv fanges opp av det materielle går studiene av materiell kultur mer og mer mot det mentale: materiell kultur som metafor, som symbol, ikon, beskjeder og tekst. Dvs. som noe annet og viktigere enn seg selv.

I arkeologien har vi selvsagt opplevd en lignende trend gjennom den såkalte "post-prosessuelle" arkeologiens postuleringen av materiell kultur som aktiv og kommunikativ (Hodder 1982a, 1982b, 1985). Faktisk kan vi si at det var med denne britiske nyorienteringen av arkeologien at mye startet på begynnelsen av 1980-tallet (med nettopp Daniel Miller som en av aktørene i miljøet rundt Ian Hodder i Cambridge, se 1985, Miller og Tilley 1984). Det var her fokus for alvor ble satt på materiell kultur som meningsbærende, som "symbols in action" (Hodder 1982b), og inspirert av den "tekstuelle vendinga" kom de litterære allegoriene snart til å florere (for eksempel "Reading material culture" (Tilley 1990), "Reading the past" (Hodder 1986), "Fra ting til tekst" (Olsen 1997)).

Denne utviklingen og introduksjonen av hermeneutiske, strukturalistiske og post-strukturalistiske perspektiv i vår fortolkning av ting var utvilsomt viktig, og jeg er overbevist om at den brakte arkeologien - og forskningen på ting - mange skritt framover. Ikke bare gikk det opp for oss at nærmest all materiell kultur kunne ha en sosial kommuniserende funksjon, men vi erkjente også tingens flertydighet og hvordan meningsproduksjonen i vel så stor grad avhang leseren og leserens kontekst som produsenten(s) (Olsen 1990). Dessverre hjalp denne kunnskapen oss ikke så mye til å forstå hva materiell kultur er, og kanskje heller ikke til å forstå hvilken rolle den på et mer grunnleggende plan spiller for den menneskelige væren. Og selv om den tekstuelle analogien utvilsomt var viktig i debatten om fortolkning, så kom vi dessverre til å ignorere forskjellene mellom ting og tekst.

Riktignok så vi etter hvert tendenser til en 
dreining bort fra det noe ensidige fokus på det symbolsk kommunikative aspektet ved materiell kultur, spesielt innenfor studier av landskap, monumenter og rom. Med basis dels i fenomenologisk tenkning, dels i Anthony Giddens og Pierre Bourdieus sosiologiske teorier, publiserte flere britiske arkeologer studier på 90-tallet som synes mer fundert i menneskenes praktiske væren-i-verden (se bl.a. Barret 1994, Bradley 1998, 2003, Tilley 1994, Thomas 1996). Fokus ble rettet mot hvordan materielle strukturer og landskap gjennom et aktiv samspill med de menneskelige aktører bidro til å forme livsløp, erfaring og hukommelse. Likevel, når man leser denne litteraturen kan man ikke helt fri seg fra følelsen av at også de neolittiske menneskene i Wessex, Cornwall og Wales primært opptrer i rollen som betraktere. At man ikke hadde stort annet å bestille enn å gå rundt i prosesjoner der man betraktet og kontemplerte landskap og monumenter fra ulike perspektiv og synsfelt. Det blir fortsatt subjektets følte, sette og bevisst fortolkende forhold til de materielle omgivelsene som står i fokus.

Den fornyete interesse for den materielle verden i arkeologi og antropologi synes dominert (og til dels legitimert) av hva vi kan kalle en "mistankens hermeneutikk" (Ricoeuer 1970), der ting, landskap og materielle strukturer generelt frakjennes en eksistens som (ikke-transcendert) materialitet og følgelig heller ikke kan innrømmes egne, iboende kvaliteter. De blir følgelig bare interessante og legitime i den grad de framtrer som "konstruerte", dvs. som diskursive objekt eller "fenomen" i menneskenes kognitive forestillingsverden. Mening stammer allid fra subjektet og i den grad tingene har betydning er det et resultat av de sosiale og kulturelle inskripsjoner vi har påført deres overflate (Boast 1996:174, Ingold 2000:340-341). Følgelig blir det nærmest en truisme å forfekte at landskap, for eksempel, er en sosial eller kulturell konstruksjon: "Landscapes are created by people - through their experience and engagement with the world around them" (Bender 1993:1). Eller som redaktørene av boken $A r$ chaeologies of landscape, uttrykker det "today... the most prominent notions of landscape emphasize its socio-symbolic dimensions: landscape is an entity that exists by virtue of its being perceived, experienced, and contextualised by people” (Ashmore og Knapp 1999:1).

I denne feiringen av landskap og materie som formelig, tvetydig og alltid konstruert (“... as something open-ended, polysemic, untidy, contestational and almost infinitely variable", Bender 2002:137), synes det å være liten sympati og forståelse for de kvaliteter og kompetanser som den materielle verden selv besitter kvaliteter som blir "effektive" i vår konkrete og innfugete omgang med den (Olsen 2003). Selv om det utvilsomt er viktig å betone betydningen av den menneskelige erfaring av de materielle omgivelsene, og at de betydninger vi tillegger dem utvilsomt varierer og endres, har vi endt opp med en påfallende asymmetrisk relasjon der all betydning og makt er samlet på et sted: hos subjektene.

Spørsmålet som nå synes betimelig er hvor lenge vår "materielle Andre" skal underlegges dette menneskelige eneveldet? Tilfører virkelig ikke de materielle omgivelsene oss noe? Preger ikke landskap og ting - også gjennom sin blotte materialitet ("an sich") - våre bevegelser, opplevelser og handlinger? Kan det være at de - og kanskje langt mer enn vi er villig til å innrømme - er sterkt medvirkende i konstitueringen av vår generelle væren-i-verden? Om du fortsatt er i tvil, still deg spørsmålet neste gang du går rundt $\mathrm{i}$ byen, beveger deg $\mathrm{i}$ din leilighet eller kjører bil på motorveien (Johansen 1991, Boast 1996, Olsen 2003). 


\section{TINGENES GLEMSEL}

La meg skifte fokus noe: Hvis tingene har slik betydning for vår væren-i-verden, hvorfor har de da i så stor grad unngått det akademiske blikk? En forsøkt forklaring er tingenes egen unnfallenhet og taushet. De er så innfelte i våre liv, "being at the same time the most obvious and the best hidden" (Lefevbre 1987:8), med andre ord for nære til å bli sett. Som Christensen og Thau skriver i forordet til boken $\mathrm{Om}$ gang med tingene:

"Der er ting overalt. Vi omgiver oss med dem; de er et så selvfølgelig inventar i hverdagen, at vi knapt registrerer dem. De har deres faste plasser, særlige bestemmelser og funktioner; de er der bare og anfægter os for så vidt ikke... De stiller seg til rådighed." (Christensen og Thau 1993:7)

Bare når de går i stykker, kommer i veien for oss eller er borte, "ser" vi tingene (Heidegger 1962:102-103, Latour 1999:183). Men slike forstyrrelser opphører, ting kommer til rette eller erstattes, for på ny å kunne gli sikkert inn i glemselens mørke.

Tingenes tatt-for-gitthet er utvilsom av stor betydning for forståelsen av vår daglige væren, men det er høyst tvilsomt om denne mundane blindhet for tingene kan forklare deres deportasjon fra forskningens arena. De fleste av oss ser ikke mito-kondrielt DNA, hekser eller sosiale strukturer, og få vil jeg tro er bevisste i sitt hverdaglige liv om grammatikkens dypstrukturer, det transcendentale Ego, for ikke å snakke om det ubevisste. Likevel har dette ikke hindret filosofien og forskningen i å være svært så opptatt av disse fenomenene.

Tingenes diasporiske skjebne kan mer plausibelt relateres til en dominerende tradisjon av ting-glemsel (og-diabolisme) i vestlig tenkning fra 1600-tallet av. Ikke minst kan den skepsis filosofien antok i kjølvannet av Descartes "metodiske tvil" hjelpe oss til å forstå hvorfor tingenes hjemkomst i disipliner som antropologi har fått et så sterkt skjær av mistankens hermeneutikk over seg. Opplysningsfilosofene, og deres "rasjonalistiske" forløpere, etterlot oss nemlig en arv der materie ble sett på som passiv og kraftløs, mens den menneskelige tanke var aktiv og kreativ. For Descartes hadde den ytre verden, dvs. materien og naturen, ingen nødvendig selvstendig eksistens; den kunne faktisk vise seg bare å være en konstruksjon i vår bevissthet (Kolstad 2001:152). Tanke og materie tilhørte uansett to atskilte sfærer, og den stadig økende kløften mellom dem ble en endeløs kilde til epistemologiske spekulasjoner om forholdet mellom vår bevissthet (og kunnskap) og den materielle verden "der ute".

Som for mye av den moderne tenkingen fikk Kants forsøk på avdekke erfaringens a prioriske strukturer en avgjørende betydning også her. Han hevdet at vi ikke kan erfare tingene direkte eller i seg selv, de framtrer bare for oss som fenomener - som foredlete produkt av vår tenkning. Som Dag Anderssson har uttrykt det, "Kant lærte oss at vi ikke kan møte tingene ansikt til ansikt: mellom tingene og oss faller skyggen av vår egen forming av tingene" (Andersson 2001:81). Vi kan med andre ord ikke forstå verden eller tingene "i seg selv", bare slik de er formet av "oss selv", dvs. av vår egen fornuft. Og til forskjell fra Aristoteles syn på menneskets skapende forhold til verden som en videreføring av dens egne former, er form og forming endt opp som rent subjektive kategorier. Opplysningstidas lærdom om menneskene som formende vesen fikk som premiss en formløs og død ytre verden (Andersson 2001:92).

Ikke bare aner vi her grunnlaget for hvorfor tingene ikke kan aksepteres i sin ikke-transcenderte materialitet (Christensen 1993:39), men 
også for deres diasporiske status i modernitetens tenkning:

"I filosofien etter Kant er tingene fordrevet fra tenkningens interessefelt... Det fordret at tingene ble utestengt fra den umiddelbare erfaringen av verden. Bare i sin abstrakte tilstand som gjenstander for vitenskap ble tingene tilbake... Tingene i seg selv, slik Kant taler om dem, befinner seg ikke lenger i den verden vi kan vite noe om. De har mistet sitt sted i verden..." (Andersson 2001:130)

Riktignok kan det hevdes at den fenomenologiske filosofien på 1900-tallet, spesielt slikt den ble utformet av Martin Heidegger og Maurice Merleau-Ponty, på ny brakte tingene inn $\mathrm{i}$ vår erfaringsverden. Både $\mathrm{i}$ sin tidlige (Veren og Tid) og seine filosofi var Heidegger sterkt opptatt av vårt forhold til tingene. Faktisk i en slik grad at han i en forelesning fra $1941 \mathrm{kla}-$ get over at folk trodde det var bare det han skrev om i sitt hovedverk Veren og tid. "For Heidegger", skal han her ironisk ha bemerket, "består verden bare av kokegryter, høygafler og lampeskjermer; han har ingen ting å si om 'høyere kultur' eller om 'natur" (sitert etter Inwood 2000:130). Likevel, som Andersson påpeker, for fenomenologene ble tingene brakt på scenen primært ut fra ønsket om å forstå det sansende og forstående subjektet, heller enn å gi stemme til tingene. Derfor, i den grad de ga "tingene anledning til å tale, er det en redigert tale" (Andersson 2001:131).

\section{FRYKTEN FOR TINGENE}

Tingenes status hadde heller ikke blitt forbedret av at de selv ble "påfallende til stede" i vår mundane livsverden fra siste halvdel av 1800tallet av. Heller tvert om. For filosofer og intellektuelle ble den omseggripende moderne teknologien og de masseproduserte tingene et tegn på hvordan verden var i ferd med å bli "tingliggjort", bli omskapt til en kald, upersonlig og inautentisk arena av Gestell hvor "the object-character of technological domination spreads itself over the earth ever more quickly, ruthlessly, and completely" (Heidegger 1971:112). De fleste av modernitetens tenkere kom derfor til å se tingenes mangfoldiggjøring (som massekultur og teknologi), som en trussel mot menneskene - og i økende grad ble kreativitet, frigjøring og autentisitet definert som det som unnslipper det materielle (Latour 2002). Det er utvilsomt at denne ting- og teknologifiendtligheten i moderne filosofi og samfunnsforskning bidro til å gi tingene en negativ og "ikke-sosial" status.

Et viktig innledende bidrag til denne tingantagonismen finner vi i Karl Marx arbeider om hvordan kapitalismens misrepresenterte og tingliggjorde sosiale relasjoner og det menneskelige arbeidet. Gjennom sitt begrep om varefetisjismen fokuserte han på hvordan markedskreftene fikk varens verdi til å framsto som uavhengig og løsrevet fra det arbeidet som er nedlagt i den. Fetisjisme var opprinnelig tilknyttet primitiv religiøs praksis, hvor steiner og trær ble tilbedt som om de var "virkelige guder". Seinere ble dette fenomen som vestlig reisende og etnografer så som en "bedragersk erstatning", utviklet av marxister og psykoanalytikere til et mer generell begrep i betydningen misrepresentasjon eller feilplassering; kort sagt, en misforståelse hvor kvaliteter og egenskaper som bare kan tillegges mennesker tilskrives ting (Christensen 1993). For marxistene (inkludert seinere tenkere som Lukács, Horkheimer and Adorno) ble det falske - og fetisjistiske - forholdet til varen og tingen symptomatisk for en mer generell prosess av fremmedgjøring i det kapitalistiske samfunnet, hvor menneskelige relasjoner og kulturelle for- 
32 mer erstattes med tingliggjorte forhold.

Selv om dette av Marx også var ment som en kritikk av hvordan tingene mistet sin sosiale verdi og menneskelige tilknytning under kapitalismen, endte marxismen opp med å forsyne samfunnsteorien med et svært tendensiøst vokabular som sterkt bidro til tingenes stigmatisering: "tingliggjøring", "objektivisering" og "instrumentell fornuft". Gjennom disse metaforene framsto tingene som symboler på de destruktive og fornedrende kreftene i det moderne samfunnet, og ga samtidig deres fordømmelse en moralsk legitimasjon. Psykoanalysens tabuisering av tingen, gjennom sine teorier om fetisjismen som en form for seksuell pervertering (en stedsfortreder - et substitutt), gjorde neppe saken bedre (Christensen 1993:41).

Tingene kom fra nå av i økende grad til å opptre i rollene som menneskenes - og humanismens - fiende nummer én. Derfor ikke så underlig, som Miller uttrykker det, at de fleste seinere kritikere av teknologi og massekultur nærmest har som aksiomatisk utgangspunkt "that the relation of persons to objects is in some way vicarious, fetishistic or wrong; that primary concern should lie with direct social relations and 'real people"' (Miller 1987:11).

\section{MIDTENS RIKE}

Hensikten med mitt forsvaret av tingene er ikke å erstatte subjekter med objekter for således å skape et nytt despoti. Det som foreslås er et mer egalitært regime, en symmetrisk arkeologi, konstituert på det premiss at verden er bebodd av både mennesker og ikke-mennesker (som dyr, planter, ting). Alle disse beboerne er beslektet, de deler materiell substans og har alle rettigheter som medlemmer av en felles verden. De er selvsagt forskjellige, men dette er en forskjellighet som ikke må kategoriseres i henhold til det herskende regimet av motsetninger og negativiteter: det er en ikke-dualistisk eller relativ forskjell som fremmer samarbeid, delegering og utveksling. Hvor langt tilbake vi enn går i den "snakkende historien og tause forhistorie" (Serres 1987:209), har mennesker utvidet sine sosiale relasjoner til ikkemenneskelige aktører, nytt godt av deres egenskaper og sammen formet kollektiver (Latour 1999:198).

Om vi ser samfunn som komplekse, heterogene nettverk som forbinder alle beboere, uavhengig av status og familieforhold, inngår også tingene som virkningsfulle - og meningsfulle - aktører. Som mange meningsfeller har hevdet (Latour 1987, 1996, 1999, 2003; Callon and Law 1997, Law and Hassard 1999, Law and Mol 2002), framtrer ikke virkeligheten i essenser, men som hybride blandinger, et sømløst vev av kulturer og naturer som forbinder mennesker og ikke-mennesker $\mathrm{i}$ intime relasjoner. For nok en gang å vende tilbake til tingglemselen, så kan den vold som det moderne regimet har utøvet mot dette nettverket av hybride relasjoner og transformasjoner utdype og utvide de momenter til forklaring som alt er gitt. Slik Bruno Latour hevder i boka $V i$ har aldri vart moderne, medførte modernitetens (eller "det modernes") tilkomst skapningen av to strengt atskilte ontologiske sektorer: menneskenes område på den ene siden, og ikkemenneskenes på den andre. Dette innebar en fundamental separasjon der menneskenes makt, interesser og politikk ble plassert ved den ene polen, mens kunnskapen om gjenstandene og det ikke-menneskelige havnet ved den andre. Fra nå av ble de delegert ulike ontologiske og disiplinære felt: på den ene siden de som beskjeftiget seg med menneskene-seg-imellom, på den andre siden de som studerte tingene-iseg-selv (Latour 1996:14-23). 
Denne dualiteten fjernet tingene fra menneskene, splittet opp blandingene de inngikk i. I kontrast til de før-moderne som hadde sauset alt sammen i en fryktelig røre av mennesker og ting, kultur og natur, ble det moderne kunnskapsregimet konstituert på vår evne til å skille mellom dem (Latour 1996:128-131). Selv om røren selvsagt aldri har vært større (hvilken side av gjerdet tilhører ozonhullet, Belgisk blå, hunderaser, elektrisiteten, internett, flyene, klaveret?), er hele vårt moderne kunnskapsbilde, inkludert dets taksonomier, tilpasset en segregert, splittet verden. Når denne graverende uoverensstemmelsen mellom selvrepresentasjon og praksis likevel har vist seg så overlevelsesdyktig, skyldes det i følge Latour at moderniteten og de ulike vitenskaper kontinuerlig skaper og vedlikeholder motsetningen. Vitenskapelig praksis har i stor grad blitt et "renselsesarbeide", der alt som eksisterer må plasseres innenfor to distinkte ontologiske sfærer, som ting eller mennesker, objekter eller subjekter (Latour 1996:103). Verden må sorteres, stykkes opp og re-arrangeres i henhold til de rette kategoriene. Det finnes med andre ord ingen disiplinær plass for hybriditeten, dette ureine både-og , dette "Midtens rike", der tingene naturlig hører hjemme.

Dette begjæret for en umiddelbar verden tømt for sine meglere, transformatorer og overløpere, etterlot tingene $\mathrm{i}$ en tvetydig posisjon innenfor det moderne regimet. De befant seg utenfor den menneskelige sfære av makt, interesser og politikk - og likevel ikke riktig natur. Selv om de var utskrevet til den ikke-menneskelige leiren, endte tingene - den materielle kulturen - opp med ikke å innta noen av de to posisjonene foreskrevet for dem av den moderne forfatningen: som enten kultur eller natur. Materiell kultur ble "a matter out of place", del av det ekskluderte mellomriket. Kan- skje finner vi her selve kimen til tingenes glemsel - og til deres fryktsomhet.

\section{UVENTET UNNSETNING}

Ordene, begrepene, utsagnene er sjelden tingenes tjenere, spesielt ikke etter at enheten mellom dem gikk tapt. Men kanskje kommer til sist ordene tingene til unnsetning, i hvert fall de ord som ennå lar tingene tale. Begrepet materiell kultur er av mange sett på som en kontradiksjon, en umulighet. Av andre sett på som en manifestasjon og videreføring av vår ontologiske dualisme. Men kanskje, og muligvis bare strategisk og foreløpig, kan nettopp dets hybride og opposisjonelle karakter (kultur som også tinglig) yte motstand til den nye "sosiale" mesterfortellingens selvsagte feiring av kultur som alltid ikke-materiell, flytende og situasjonell. Slik sett bør det i hvert fall kunne brukes i selvforsvar.

Et mer grunnleggende forsvar for tingenes betydning borger selve ordet ting for. Dets etymologi viser nettopp til tingens samlende og transformative kvaliteter. Som flere forskere har pekt på (se Heidegger 1971:172, Glassie 1999:67-68), var betydningen av det gammelnorske og gammelengelske ordet ping, i likhet med det gammel høytyske Thing, "forsamling" eller møte. Mindre, kjent (dog mer usikkert) er det at en eldre etymologisk rot (tenku) i tillegg antyder en samling av tid: i betydningen "varighet" eller mer bokstavelig "utvidet" eller "strukket" tid (Falk and Torp 1906:903; Bjorvand and Lindeman 2000:939ff). Men andre ord, tingen er det som samler, bringer sammen og som varer: den forbinder kvaliteter og enheter i tid og rom. Det perfekte ledd i et nettverk. Kanskje gir disse glemte betydninger håp om en ny forfatning, et nytt demokrati, der også gjenstandene har sin plass. Og der men- 
34 neskene får tilbake sin tapte del av seg selv: tingenes andel.

\section{LITTERATUR}

Andersson, D. T. 2001. Tingenes taushet, tingenes tale. Solum Forlag, Oslo

Ashmore, W. and A. B. Knapp 1999. Archaeological landscapes: constructed, conceptualised, ideational. I Ashmore, W. and A. B. Knapp (red.), Archaeologies of landscape: contemporary perspectives. Blackwell, Oxford.

Attfield, J. 2000. Wild things. The material culture of everyday life. Berg, Oxford-New York

Barret, J. 1994. Fragments from Antiquity. Blackwell, Oxford.

Barth, F. 1961. Diffusjon - Et tema i studiet av kulturelle prosesser. I Arne Martin Klausen (red.): Kultur og Diffusjon, Universitetsforlaget, Oslo.

Bender, B 1993. Introduction. In Bender, B. (red.), Landscape: Politics and perspectives. Berg, Oxford

Bender, B. 2002. Landscape and politics. I Buchli, V. (red.), 2002. The material culture reader. Berg, Oxford.

Bjorvatn, H., Lindeman, F.O. 2000. Vare arveord. Etymologisk ordbok. Novus Forlag, Oslo.

Boast, R. 1996. A small company of actors: a critique of style. Journal of Material Culture 2(2):173-198.

Bradley, R. 1998. The significance of monuments. Routledge, London.

Bradley, 2003. Seeing things: Perception, experience and the constraints of excavation. Journal of social archaeology 3(2):151-168.

Brown, B. 2003. A sense of things. The object matter of American literature. The University of Chicago Press; Chicago and London.

Buchli, V. (red.), 2002. The material culture reader. Berg, Oxford-New York.

Callon, M. and Law, J. 1997. After the individual in society. Lessons on collectivity from science, technology and society. Canadian Journal of sociology 22(2):165-182.

Christensen, C. L og Thau, C. (red.),1993. Omgang med tingene. Ti essays om tingenes tilstand. Arhus Universitetsforlag, Arhus.

Christensen, C.L. 1993. Tingenes tidsalder. Kitsch, camp og fetichisme. I Christensen, C. L og Thau, C. (red.),1993. Omgang med tingene. Ti essays om tingenes tilstand. Århus Universitetsforlag, Århus.

Dant, T. 1999. Material culture in the social world. Values, activities, lifestyles. Open University Press, Buckingham, Philadelphia.

Falk, H. and Torp, A. 1906. Etymologisk ordbog over det norske og det danske sprog. Kristiania.

Gjessing, G. 1951. Arkeologi og etnografi. Viking $\mathrm{XV}: 115-136$.

Glassie, H. 1999. Material culture. Indiana University Press, Bloomington and Indianapolis.

Handler, R. 2003. Cultural property and cultural theory. Journal of Social Archaeology 3 (2): 353365.

Heidegger, M. 1962. Being and time. Harper \& Row, New York.

Heidegger, M. 1971. Poetry, language, thought. Harper \& Row, New York.

Hodder, I. (red.) 1982a. Symbolic and structural archaeology. Cambridge University Press, Cambridge

Hodder, I. 1982b. Symbols in action. Cambridge University Press.

Hodder, I. 1985. Post-processual archaeology. Advances in archaeological method and theory 8:1-26.

Hodder, I. 1986. Reading the past: current approaches to interpretation in archaeology. Cambridge University Press, Cambridge.

Ingold, T. 2000. Perception of the environment. Essays in livelihood, dwelling and skill. Routledge, London.

Inwood, M. 2000. A Heidegger dictionary. Blackwell, Oxford.

Johansen, T. 1992. Kulissenes regi. En sosiomateriell analyse av forutsetningene for makt og mestring.

Universitetsforlaget, Oslo. 
Kolstad, H. 2001. Henri Bergsons filosofi - betydning og aktualitet. Humanist forlag, Oslo.

Law, J and Hassard, J. 1999 (red.). Actor network theory and after. Blackwell, Oxford.

Law, J. 1999. After ANT: complexity, naming and topology. In Law, J and Hassard, J. 1999 (red.). Actor network theory and after. Blackwell, Oxford.

Law, J. and Mol, A. 2002 (red.). Complexities. Social studies of knowledge practices. Duke University Press, Durham, NC.

Latour, B. 1987. Science in action: How to follow scientists and engineers through society. Harvard University Press, London/Cambridge, Massachussets.

Latour, B. 1996. Vi har aldri vert moderne. Spartacus Forlag, Oslo.

Latour, B. 1999. Pandora's hope. Essays on the reality of science studies. Harvard University Press, London/ Cambridge, Massachussets.

Latour, B. 2002. Bodies, Cyborgs and the Politics of Incarnation. In S. Sweeney and I. Hodder, The Body. Cambridge, Cambridge University Press.

Latour, B 2003. Is Re-modernization occurring? Theory, Culture and Society 20 (2):35-48.

Leach, E. 1973. Concluding address. In C. Renfrew (red.), The explanation of culture change: models in prehistory. University of Pittsburg Press, Pittsburg.

Lefebvre, H. 1987. The everyday and everydayness. Yale French Studies vol 73 (fall): 7-11.

Löfgren, O. 1997. Scenes from a troubled marriage. Swedish ethnology and material culture studies. Journal of Material Culture 2 (1): 95-113.

Miller, D. 1985. Artefacts as categories. Cambridge University Press, Cambridge.

Miller, D. 1987. Material culture and mass consumption. Blackwell, Oxford.

Miller, D. 1998a. Why some things matter. In D. Miller (red.), Material cultures. Why some things matter. University College London Press, London.

Miller, D. 1998b. A theory of shopping. Polity, Cambridge.

Miller, D. 2002. Consumption. In V. Buchli (red.),
The material culture reader. Berg, Oxford-New York.

Miller, D. og C. Tilley (red.) 1984. Ideology, power and prehistory. Cambridge University Press, Cambridge

Olsen, B. 1990. Roland Barthes: from sign to text. In C. Tilley (red.): Reading Material Culture, Blackwell, Oxford.

Olsen, B. 1997. Fra ting til tekst. Teoretiske perspektiv $i$ arkeologisk forskning. Universitetsforlaget, Oslo.

Olsen, B. 2003. Material culture after text: Re-membering things. Norwegian Archaeological Review 36 (2): 87-104

Ricoeur, P. 1970. Freud and philosophy: an essay on interpretation. New Haven, Yale University Press.

Serres, M. 1987. Statues. Bourin, Paris.

Serres/Latour (M. Serres with B. Latour) 1995. Conversation on science, culture and time. The University of Michigan Press, Ann Arbor.

Thomas, J. 1996. Time, culture and indentity. An interpretive archaeology. Routledge, London.

Tilley, C. (red.) 1990. Reading Material Culture, Blackwell, Oxford.

Tilley, C. 1994. A Phenomenology of landscape. Berg, London.

Welsch, W. 1997. Undoing aesthetics. Sage, London.

\section{SUMMARY}

\section{Steps towards a defense of things}

The main concern of the paper is to discuss why things and materiality at large to such an extent have become marginalized - and even stigmatised - in contemporary social research. It starts off with a brief sketch of how this negative attitude towards things came to affect my own discipline, archaeology. Way back in time archaeologists loved material culture - one may even recall a certain obsession. In fact, it was a concern shared by several disciplines. However, our former allies soon abandoned the world of things and embraced the world of cultures, social systems, and ideas, accessible 
36 only, as we were told, by dialogue and participant observation. Throughout the first three quarter of the $20^{\text {th }}$ century, anthropologist repeatedly reminded us that "in the last analysis, archaeology must be concerned with people rather than with things" (Leach). Thus, to study "just things" became a source of embarrassment.

The new interest in material culture witnessed in a number of disciplines during the last two decades can be read as a rehabilitation of things. It is argued, however, that the "new" material culture studies still keep thing's materiality (or thinglyness) firmly at arm's length and have subsumed themselves to hegemonic anti-material and social constructivist theories. If material culture has returned, it is as symbols, metaphors and texts. A subtext in most contemporary approaches is an implicit conception of culture as somehow "prior" to, or detached from, matter; that cultures, "already different", approach the material world in unique ways causing the variety of material expressions and meanings. Material culture and landscapes are read as sites of "inscription", as semiotic constructs always representing something else and more important than themselves.

Trying to answer the question of why the physical and "thingly" component of our past and present being to such an extent forgotten or ignored in contemporary social research, the author traces an effective history back to the Enlightenment legacy. This legacy (pace Kant and Descartes) left us with a notion of matter as passive and inert, while the human mind was seen as active and creative. Matter and mind belonged to separate realms, and the widening gulf between them made it impossible to grasp the things in-themselves. Thus, they were exiled from the knowable world. The curious fact that things became "conspicuously" present in the mundane world from the late $19^{\text {th }}$ century onwards did not help much to their reputation. To the contrary, as philosophers and social theorists grew increasingly concerned with processes of withering and change: how mass production, factories and machines replaced craftsmanship and manual labour, and how social relationships, including labour and exchange, become increasingly mediated by the "emptiness" of money and commodities, things became symbols of these evil forces. Tellingly manifested in the Marxist (and social theorist) vocabulary of dinglich machen, versachlichung. Things became increasingly associated with alienation, dehumanisation, automatisation and inauthentic being, also as reflected in the "problematic" of the fetish.

This paper is written as a defence of things. Inspired by various "network" approaches I propose a "symmetrical approach" (pace Latour) conveying the message that if we cease to treat action, influence and power as a rare commodity of which only humans have possession, we may be able produce a more fair, interesting and realistic account of past and present collectives. Things, places and landscapes do not just sit in silence awaiting to be embodied with socially constituted meanings, but possess their own unique qualities and competences which they bring to our cohabitation with them - competences which facilitate a mutual exchange. If we accept that social reality consists of heterogeneous networks, co-acting webs of relations linking all kinds of materials, also things are assigned the properties to act. Returning again and finally to the concern expressed in the beginning, it is argued that a more fundamental cause for the silencing of things is to be found in the way the modern ontological constitution (by supplying us with such a priori dualities as mind-matter, culturenature) has violated this relational and rhizome-like reality. This ontology can only be legitimised by processes cleansing, by splitting the mixtures apart in order to extract from them what comes from culture and what comes from nature. This passion for purity and negativities assigned things (as hybrids, works of translation) an ambiguous position within the modern constitution. In short, they become matter out of place.

Bjørnar Olsen, professor i arkaologi ved Tromsø Universitet Adresse: Inst. for samfunnsvitenskab, Universitetet, $N$ 9037 Tromsø.

E-mail:bjornaro@isv.uit.no 